\title{
Efficacy of a Speech-Language Development and Disorders Awareness Lecture among Pre-Primary School Teachers in Lucknow
}

\author{
Anne Varghese ${ }^{1}$, Tripti Ojha ${ }^{2}$ \\ ${ }^{1}$ Professor, Dr M.V. Shetty College of Speech and Hearing, Maladi Court, Kavoor, Mangalore - 575015, \\ Karnataka, India. \\ ${ }^{2}$ MASLP, Nurture Clinic, First Floor, Nishatganj, Mahanagar, Lucknow - 226066, Uttar Pradesh, India.
}

Corresponding Author: Anne Varghese

\begin{abstract}
Aim: The aim of the study was to measure the efficacy of an awareness lecture on speech and language development and disorders among pre-primary school teachers of Lucknow.

Method: The study was carried out in 2 phases. In Phase I the questionnaire on the speech and language development and disorders and a lecture on speech and language development and disorders were prepared. The questionnaire contained questions on the components of speech and language, and on the importance of language for literacy and academic success. The lecture contained information on the components of speech, language and communication; the development of speech and language and its disorders; and the relationship between speech and language skills and academic success. In Phase II, the questionnaire was administered on 30 pre-primary school teachers before conducting and after conducting the awareness lecture on speech and language development and disorders in children.

Results: The results demonstrated significant improvement in the mean scores on awareness of speech, language development and disorders post-lecture showing that the study was successful in creating awareness of speech and language development and disorders among the pre-primary school teachers of Lucknow.

Conclusion: Creating awareness on speech, language development and disorders among teachers will facilitate early identification and timely intervention of children with communication disorders. Policies that promote orientation and training of positive strategies for speech, language and communication among ASHA workers and Aganwadi teachers will go a long way in early identification and intervention in India.
\end{abstract}

Keywords: Awareness, Efficacy, Teachers, Communication Disorder, Development

\section{INTRODUCTION}

Communication disorders are a broad term referring to disorders of speech, language and communication. These conditions affect an individual's ability to comprehend and/or speak in order to engage in discourse effectively with others and it arises due to various reasons. A communication disorder impacts the development of a child's foundational skills, such as, communication, social, emotional and educational ${ }^{[1,2,3,4,5]}$ and is a matter of great concern as these skills are typically attained during the pre-school years.

Children identified with speech sound disorders during childhood are reported to experience social, emotional and academic challenges that persist beyond their adolescent years ${ }^{[1,2]}$. Children with a history of language impairment in childhood also are reported to manifest continued deficits in the areas such as communication, cognitive, academic, educational achievement and vocational aspects into 
adulthood [3, 4, 5]. Academic and related issues are found to persistent into adulthood in persons with childhood language impairment as compared to persons with childhood speech impairment ${ }^{[3,4,5]}$. Early onset oral language impairment creates a broad range of deficits that impacts an individual's educational achievement, personality and social skills across lifespan.

Oral language development in children is important for future literacy development. Pre-schoolers, who have difficulties with early literacy skills such as, letter identification, sentence imitation, rapid naming and phonological awareness skills, are at risk for delayed acquisition of the later literacy skills ${ }^{[6,7]}$. Early literacy knowledge sets the foundation for the attainment of later literacy skills, that is, mastery in reading and writing. Since communication disorders have ramifications on children's future literacy development and academic success, early identification and intervention of children with speech, language and communication impairment in schools is a must. Early intervention contributes towards effective management of communication disorders and the problems associated with it ${ }^{[6,7]}$. For some children it is the means of catching up with their peers and performing well and for others it is the support system to handle academics into the higher grades ${ }^{[8]}$ and prevent school dropout.

Studies show that public's level of understanding of the importance and implications of communication disorders is low $[9,10,11]$. Raising awareness is an important aspect in the development of a society. Awareness programs are essential for fostering positive attitudes towards persons with disabilities ${ }^{[12,13,14]}$. Creating awareness in a community has been found to reduce the prevalence of any disability. Lack of awareness is found to pose challenges in the life of persons with disabilities thereby, affecting their quality of life. Superstitious beliefs, lack of education, poor socio-economic status, distance from the source of information and poor access to mass media are thought to be the major reasons for lack of awareness about communication disorders ${ }^{[15,16]}$. Awareness is typically raised by explaining issues and disseminating knowledge to people so that they can make their own decisions. Awareness can be developed at different levels in various ways. Some of the means for creating awareness amongst the caretakers of persons with communication disorders and concerned professionals are through orientation programs for various professional and non-professional target groups, performing street plays/tableau and distributing Public Education Materials (PEM), creating educational modules on different disorders for public education etc $[12,13,14]$.

The level of awareness of communication disorders among school teachers is low ${ }^{[9,10,11]}$. Teachers of the preprimary school are the first to come in contact with children with communication disorders when they enter pre-school. These teachers need to be sensitized about communication disorders. They need to be provided training on the normal aspects of speech, language and communication development and disorders. Such information will equip the teachers with the skills necessary to identify children with disorders of speech, language or communication on time and to direct the parents of these children to avail the intervention services that their child stands in need of. Programs focussing on building a pre-primary school teacher's knowledge of speech and language development and disorders will go a long way towards contributing to early identification and intervention of communication disorders among pre-primary school children.

The aim of the study is to create awareness on speech, language and communication development and disorders among pre-primary school teachers of Lucknow by administering a questionnaire before conducting and after conducting an awareness lecture on speech and language development and disorders. 
Anne Varghese et.al. Efficacy of a speech-language development and disorders awareness lecture among preprimary school teachers in Lucknow.

\section{MATERIALS AND METHODS}

The study was carried out in two phases, Phase I and Phase II

\section{Phase I}

\section{Material development}

1) Developing the questionnaire to measure the awareness of speech and language development and disorders of speech, language and communication among pre-primary school teachers, and,

2) Preparing the lecture on speech and language development and disorders of speech, language and communication for pre-primary school teachers.

\section{Phase II}

\section{Conducting the awareness lecture}

1) Administration of the questionnaire on awareness of development of speech and language and disorders of speech, language and communication on the preprimary school teachers.

2) Delivery of the lecture on awareness of speech and language development and disorders of speech, language and communication for the pre-primary school teachers.

3) Re-administration of the questionnaire on awareness of speech and language development and disorders of speech, language and communication on the preprimary school teachers.

\section{Phase I}

\section{Material development}

\section{Questionnaire:}

A questionnaire on the components of speech and language and its development and disorders of speech, language and communication was prepared. The questionnaire included questions on importance of language for literacy and for academic success in school. Four options, they are, poor, fair, average and good, were provided from which to select the responses. The responses carried a score of $1,2,3$ or 4 respectively.

\section{Awareness Lecture:}

The lecture on speech and language development and disorders was prepared. It described both the stages of speech and language development, and the disorders associated with each speech, language and/or communication skill. Images and audio clips were included to provide examples of both the normal and disordered speech, language and communication patterns.

\section{Phase II \\ Conducting educational program Subjects}

The participants consisted of 31 female pre-primary school teachers aged between 25-42 years and mean age 29.64 years from 5 urban schools within Lucknow. The years of experience as teacher ranged from 5 to18 years, Table 1 .

Table 1 The age, gender and years of experience of teachers participating in the study

participating in the study
\begin{tabular}{|l|l|l|l|l|}
\hline $\begin{array}{l}\text { SI } \\
\text { No }\end{array}$ & No & $\begin{array}{l}\text { Mean } \\
\text { (Years) }\end{array} \quad$ Age & Gender & $\begin{array}{l}\text { Experience } \\
\text { (Years) }\end{array}$ \\
\hline 1 & 31 & 29.64 & Female & $5-18$ \\
\hline
\end{tabular}

\section{Inclusion criteria}

Teachers with a minimum of three years of experience in pre-primary school teaching were selected.

\section{Materials}

1) Questionnaire on the speech and language development and disorders of speech, language and communication from phase I and,

2) Awareness Lecture prepared in phase I.

\section{Procedure}

Prior permission was taken from the school authorities to conduct the study. On the scheduled day, the study was conducted in the following manner.

The study was conducted in a quiet room. The experimenter was introduced and the purpose of the visit explained. To build rapport with the participants a few minutes of interaction was held. Next, the questionnaires were distributed and the participants were instructed to answer them. 
The completed questionnaires were kept aside, and the previously prepared lecture on speech and language development and disorders of speech, language and communication was delivered via power point presentation. On completion of the lecture the questionnaire on awareness of speech and language development and disorders was re-administered. The completed questionnaires were collected.

\section{Analysis}

The responses were analysed and tabulated.

\section{Statistical Analysis}

The descriptive statistics Mean, Standard deviation, Median and frequencies were computed. The total scores were subjected to Shapiro Wilk tests for normality. The results revealed the data was significantly deviating from normal distribution (i.e., $\mathrm{p}<0.05$ ). Therefore, a nonparametric Wilcoxon Signed rank test was carried out to look for significant differences between pre and post-lecture total scores.

Since each question was on an ordinal scale, the nonparametric Wilcoxon Signed rank test was carried out to study the changes in pre to post-lecture responses to questions for each question. To get more insight and to check qualitatively the improvement in awareness after the training the frequencies and percentage of responses were observed from pre to post. All p-values are compared with 0.05 or 0.01 level of significance. All statistical analysis is carried out using SPSS.

\section{RESULTS}

Figure 1 shows that the mean preawareness lecture score was 27.06 and the mean post-awareness lecture score was 39.87, and the difference between the means of the pre and post lecture scores was highly significant statistically $(\mathrm{z}=4.88 ; \mathrm{p}<0.01)$ Table 2.

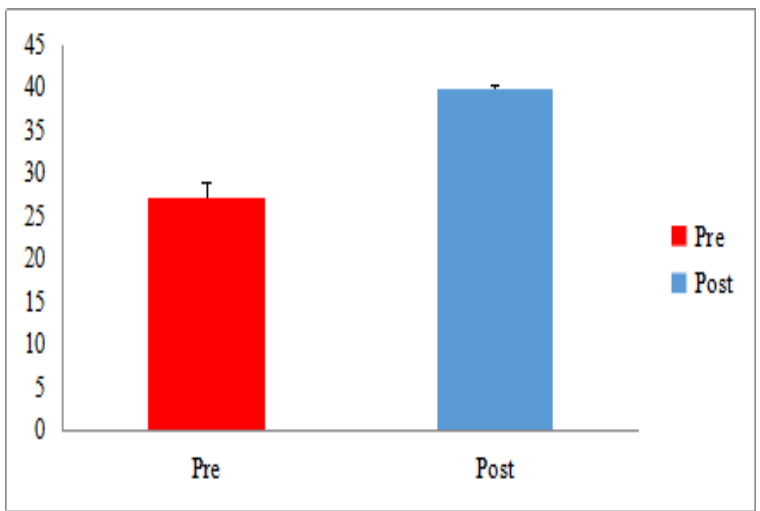

Figure 1 Overall pre and post awareness lecture mean scores

Table 2 Mean, SD, $z$ score and $p$ value of mean pre and post lecture scores

\begin{tabular}{|l|l|l|l|l|}
\hline Pairs & Mean & SD & Z & P-value \\
\hline Pre & 27.06 & 1.86 & 4.88 & $0.000^{*}$ \\
\hline Post & 39.87 & 0.42 & & \\
\hline \multicolumn{5}{|c}{$*$ Indicates significance at $p<0.01$} \\
\end{tabular}

\section{1) The pre and post awareness lecture scores for the 11 questions}

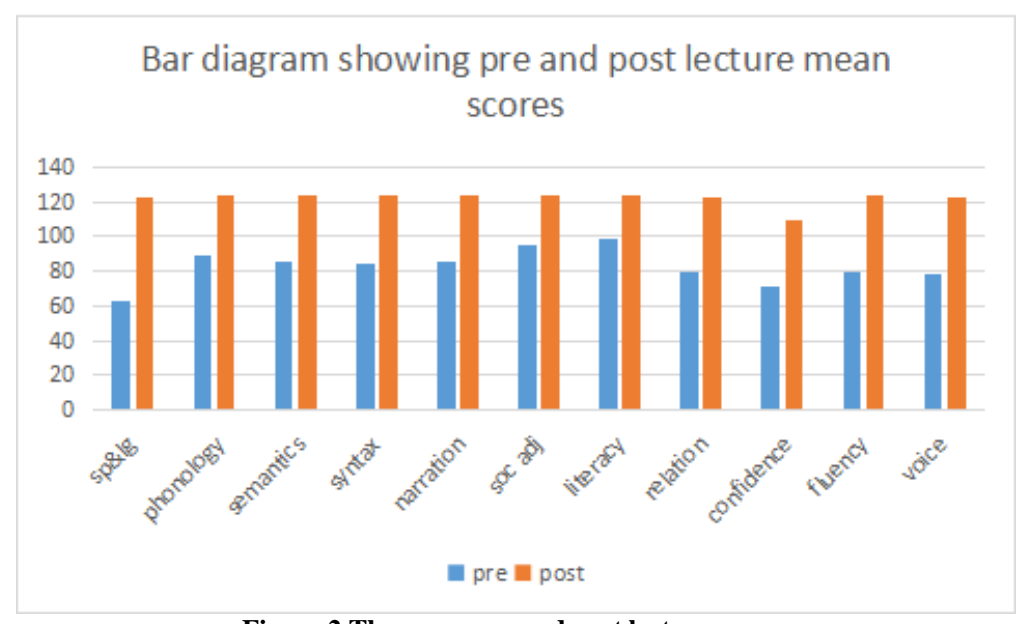

Figure 2 The mean pre and post lecture scores

Figure 2 depicts the pre and post awareness lecture mean scores for the eleven questions. For the first question on knowledge of speech and language the mean 
scores improved from 63 to 122 . For the second question on knowledge of phonology the mean scores improved from 89 to 124 . For the third question on knowledge of semantics the mean scores improved from 86 to 124. For the fourth question on knowledge of syntax the mean scores improved from 84 to 124 . For the fifth question on knowledge of narratives the mean scores improved from 86 to 124 . For the sixth question on importance of social adjustment for school readiness the mean scores improved from 86 to 124 . For the seventh question on importance of language skills for literacy skills the mean scores improved from 95 to 124 . For the eighth question on relation between language and academic skills the mean scores improved from 80 to 123 . For the ninth question on confidence in identifying speech and language skills in children the mean scores improved from 71 to 109 . For the tenth question on fluency difficulties the mean scores improved from 79 to 124 . For the eleventh question on problems with voice the mean scores improved from 78 to 123 .

\section{2) The pre and post presentation responses which changed from 3 (average) to 4 (good)}

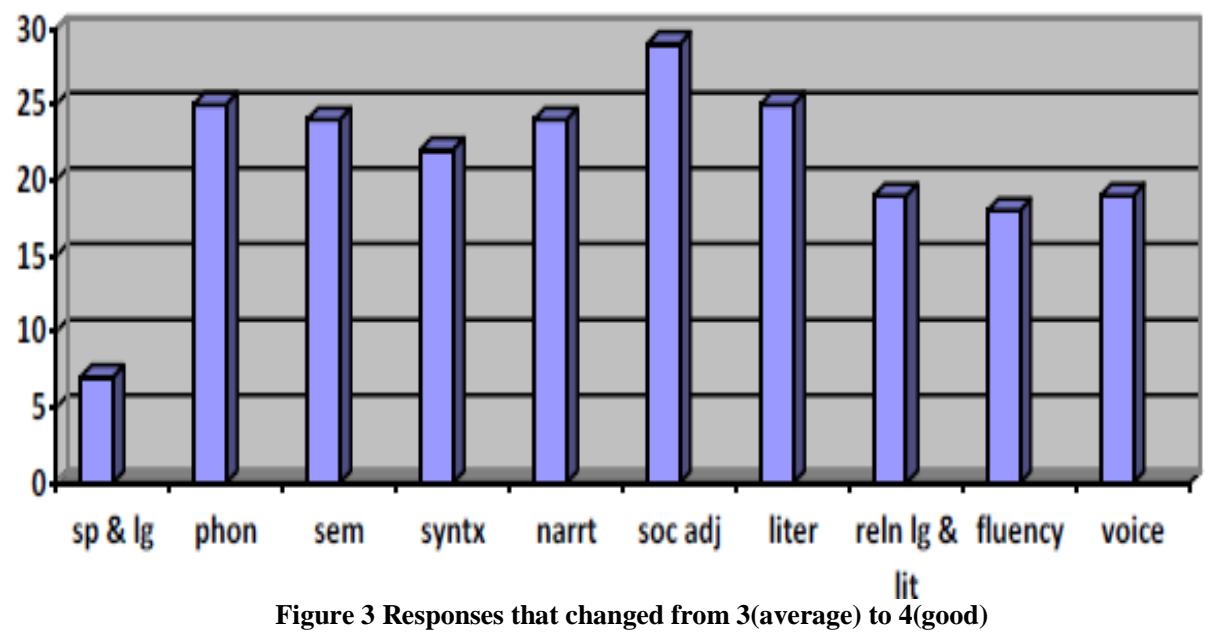

Figure 3 depicts the number of responses that changed from score 3 (average) to score 4 (good) for the 11 questions. For the question on knowledge of speech and language $7(22 \%)$ participants improved their scores from 3 to 4 . For the second question on knowledge of phonology $25(80 \%)$ participants improved their scores from 3 to 4 . For the third question on knowledge of semantics 24(77\%) participants improved their scores from 3 to 4. For the fourth question on knowledge of syntax $22(71 \%)$ participants improved their scores from 3 to 4 . For the fifth question on knowledge of narratives 24(77\%) participants improved their scores from 3 to 4. For the sixth question on importance of social adjustment for school readiness 29(93\%) participants improved their scores from 3 to 4 . For the seventh question on importance of language skills for literacy skills 25(80\%) participants improved their scores from 3 to 4 . For the eighth question on relation between language and academic skills $19(61 \%)$ participants improved their scores from 3 to 4 . For the tenth question on fluency difficulties 18(58\%) participants improved their scores from 3 to 4 . For the eleventh question on problems with voice $19(61 \%)$ participants improved their scores from 3 to 4 .

\section{3) The pre and post presentation responses which changed from 2 (fair) to 4 (good)}

In Figure 4 the number of responses that changed from score 2 (fair) to 4 (good) is observed. For question 1 on speech and language 18 (58\%) participants' scores improved from 2 to 4 . For question 2 on 
phonology 5 (16\%) participants' scores improved from 2 to 4 . For question 3 on semantics 7 (22\%) participants' scores improved from 2 to 4 . For question 4 on syntax 9 (29\%) participants' scores improved from 2 to 4 . For question 5 on narration 7 (22\%) participants' scores improved from 2 to 4 . For question 8 on relation between language and academic skills 1 (3\%) participants' score improved from 2 to 4 . For question 10 on fluency 12 (38\%) participants' scores improved from 2 to 4 . For question 11 on voice 9 (29\%) participants' scores improved from 2 to 4 .

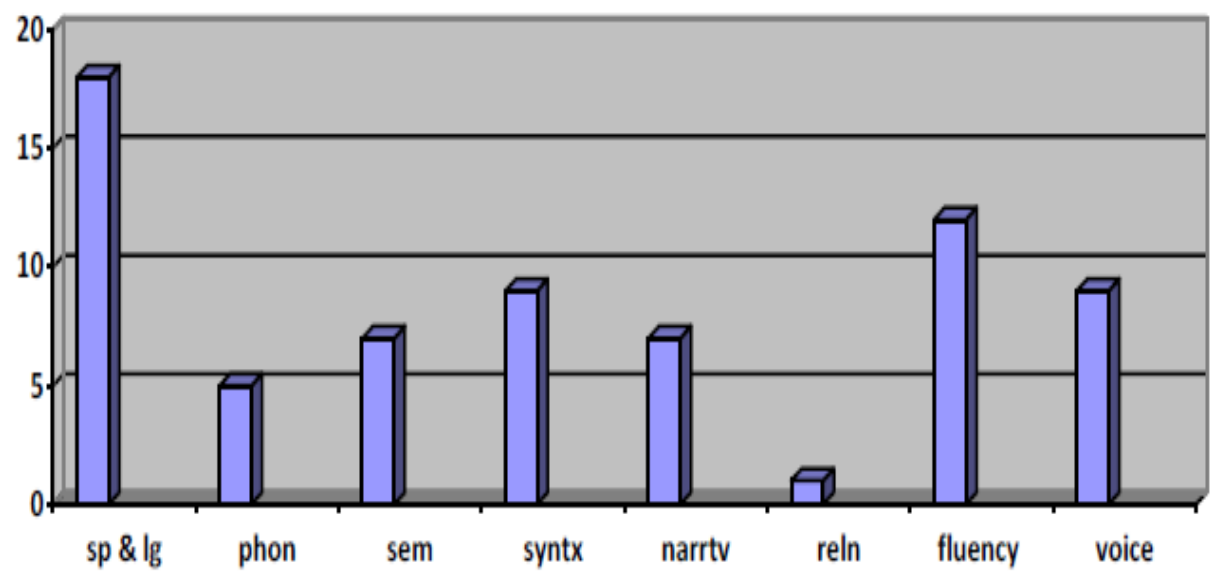

Figure 4 Responses which changed from 2 (fair) to 4 (good)

\section{4) The pre and post presentation responses which changed from 1 (poor) to 4 (good)}

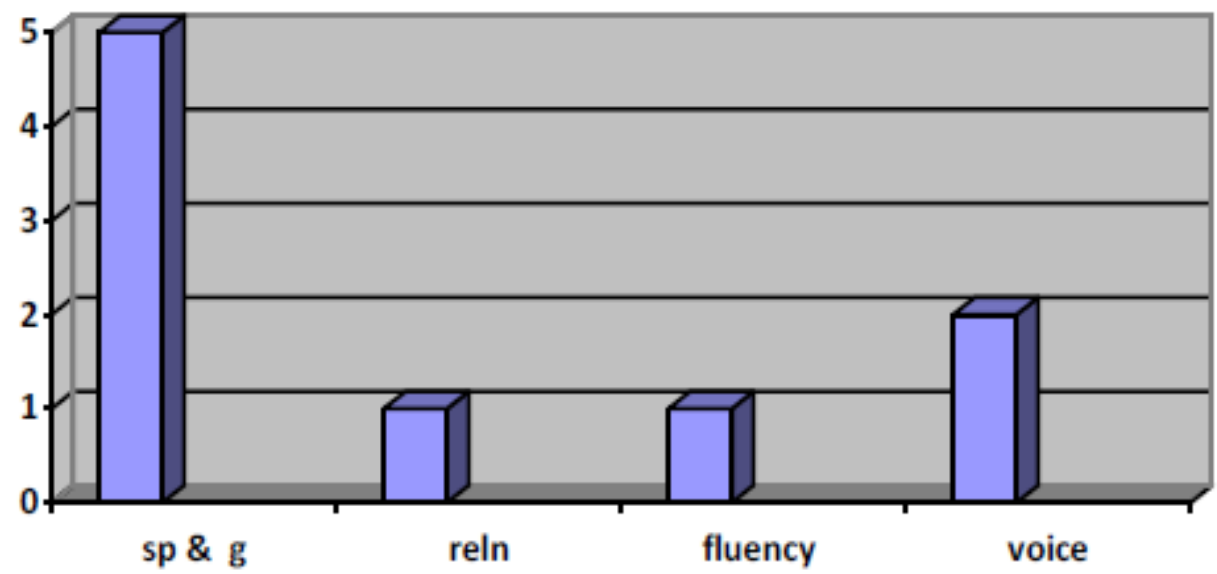

Figure 5 Responses which changed from 1(poor) to 4(good)

In Figure 5 the number of responses that changed from score 1 (poor) to 4 (good) is observed. For question 1 on speech and language $5(16 \%)$ participants' scores improved from 1 to 4 . For question 8 on relation between language and academic skills 1(3\%) participants' score improved from 1 to 4 . For question 10 on fluency 1 (3\%) participants' score improved from 1 to 4. For question 11 on voice $2(6 \%)$ participants' scores improved from 1 to 4 .

\section{5) The pattern of responses on the $9^{\text {th }}$ question}

For question 9, on confidence in identifying children with speech and language delay, 11(35\%) participants reported that their confidence increased from 3 (average) to 4 (good); 18(58\%) participants reported that their confidence increased from 2 (fair) to 3 (average) and $2(6 \%)$ participants reported that their 
confidence increased from 1 (poor) to 3 (average).

\section{6) The response on the $12^{\text {th }}$ question}

For question 12 on feedback on awareness talk 30 (97\%) participants reported that the talk was very useful and 1 (3\%) participant reported that the talk was useful.

\section{DISCUSSION}

The aim of the study was to measure the efficacy of speech and language development and disorders awareness lecture among nursery school teachers in Lucknow. Overall, the results show that there is a significant difference between the means of the pre-awareness lecture scores and post-awareness lecture scores for all eleven questions. Therefore, the study was successful in creating awareness for speech and language development and disorders among pre-school teachers of Lucknow.

The predominant direction of change of response was from 'average' to 'good' for the pre-lecture to post-lecture responses. The pre-lecture response 'average' indicates that the many of the participants felt that they had some prior knowledge about speech and language development and disorders before the lecture. The postlecture response 'good' indicates that in spite of feeling that they knew something prior to the lecture they reportedly experienced a gain in knowledge after the lecture. It is possible that the prior knowledge may have been inadequate for some, contained misinformation for some others or been inaccurate for others. For this group of participants the lecture helped fill gaps in knowledge, quell myths, clear doubts and provide accurate information on speech and language development and disorders. In a smaller group of participants the pre-lecture to post-lecture responses changed from 'fair'/ 'poor' to 'good'. This group of participants appear to have received the information on speech and language development and disorders for the first time during the lecture. Majority of the participants reported that they felt confident about identifying children with speech, language and communication disorders in the future. All the participants found the lecture very informative and useful. Studies have reported improvement in knowledge and competence post training programs conducted on selected groups $[12,13$, 14] for the purpose of imparting specific information.

The heads of the institutes also attended the lecture and were impressed, therefore, they invited the experimenter to teach, train and equip the teachers with knowledge on communication disorders the following year. They also requested the experimenter's contact details to help with children whom they identified as having misarticulation, language delay, stuttering and autism in their school. They expressed the desire that their teachers be trained to identify children with poor speech, language and/or communication skills on time and provide them the right kind of intervention. This validates the need to train teachers about language disorders and how to identify speech, language and communication disorders in a classroom for early identification and effective intervention and thereby prevent long term academic and social disadvantage. Trainee teachers could be provided with knowledge on speech, language and communication skills in order to be able to promote positive speech, language and communication strategies within any subject area. Besides literacy, teachers could also focus on speech, language and communication skills to impart effective access to the whole curriculum ${ }^{[6]}$.

An orientation program conducted on communication disorders for ASHA workers belonging to three different districts of Karnataka - Mysuru, Mandya and Chamrajanagar - on the causes, characteristics, signs, symptoms, prevention and management of speech and language disorder in children and adults showed a significant increase in the mean scores for knowledge on communication disorders ${ }^{[17]}$. 
Anne Varghese et.al. Efficacy of a speech-language development and disorders awareness lecture among preprimary school teachers in Lucknow.

Similarly, if training programs could be conducted for Aganwadi teachers across the country, it would go a long way in early identification and management of communication disorders in India.

\section{CONCLUSION}

In conclusion, there is a need to create awareness on speech and language development and disorders among the general public and in particular the preprimary school teachers. It is also desirable that both ASHA workers and Aganwadi teachers be provided orientation and training on positive speech, language and communication strategies in children, as early identification and intervention leads to successful rehabilitation of children with communication disorders.

\section{Acknowledgement: None}

\section{Conflict of Interest: None}

\section{Source of Funding: None}

\section{Ethical Approval: Approved}

\section{REFERENCES}

1. McCormac J, McLead S, McAllister L, Harrison LJ. A systematic review of the association between childhood speech impairment and participation across the lifespan. Int J Speech-Lang Path. 2009;11(2): 155-170.

2. Hitchcock E, Byun TM. Social, emotional and academic impact of residual speech errors on school-age children: A survey study. Semin Speech Lang. 2015;36(4):283294.

3. Young AR, Beitchman JH, Johnson C, Douglas L, Atkinson L, Escobar M Wilson B. Young adult academic outcomes in a longitudinal sample of early identified language impaired and control children. J Child Psychol Psychiat.2002; 43:635-645. doi:10.1111/1469-7610.00052.

4. Lewis BA, Freebaim L, Ciesla AA, Iyengar SK, Stein CM Taylor HG. Adolescent outcomes of children with early speech sound disorders with and without language impairment. Am J Speech-Lang Pathol.
2015; 24: 150-163. doi:10.1044/2014_AJSLP-14-0075

5. Johnson CJ, Beitchman JH, Brownlie EB. (2010). Twenty year follow up of children with and without speech-language impairment: Family, educational, occupational and quality of life outcomes. Am J Speech-Lang Pathol. 2010;19:51-65. doi:10.1044/1058-0360(2009/08-0083)

6. Catts H, Fey M, Zhang X, Tomblin JB. Estimating the risk of future reading disabilities in kindergarten children: A research-based model and its clinical implementation. Lang Speech Hear Serv Sch. 2001; 32: 38-49.

7. Janus M, Labonte C, Kirkpatrick R, Davies $\mathrm{S}$, Duku E. The impact of speech and language problems in kindergarten on academic learning and special education status in grade three. Int $\mathbf{J}$ Speech Lang Path. 2017; https://doi.org/10.1080/17549507.2017.138 1164.

8. Thatcher K, Fletcher K, Decker B. Communication disorders in the school: Perspectives on academic and social success an introduction. Psychol Sch. 2008;45(7): 579-581. doi:10.1002/pits.20310

9. Verma H, Janaki B, Ravichandran A. Awareness, attitude and knowledge about hearing impaired among regular school teachers: Survey across Hyderabad. Amity International Journal of Teacher Education. 2017;3(1)

10. Chandrabose J, St Louis KO, Pushpavathi $\mathrm{M}$, Raof S. Awareness of stuttering among prospective teachers of Mysore. Journal of All India Institute of Speech and Hearing. 2010; 29(2).

11. Basim AC, Fysal N, Thasneem AA Aswathy PS. Assessment of knowledge on learning disability among primary school teachers. Int J Contemp Pediatrics. 2019; $6(2)$

12. Krishnan R, Ram D, Hridya VM, Santosh AJ. Effectiveness of psychoeducation on psychological well-being and selfdetermination in key caregivers of children with intellectual disabilities. Indian Journal of Psychiatric Social Work. 2018; 9(1):4-11

13. Karande S, Patil S, Kulkarni M. Impact of an educational program on parental knowledge of cerebral palsy. Indian $\mathbf{J}$ Pediatrics. 2008;75(9):901-906. 
Anne Varghese et.al. Efficacy of a speech-language development and disorders awareness lecture among preprimary school teachers in Lucknow.

14. Shunmugam S, Subramaniyan B, Nagarajan R, Hariharan SV. Effectiveness of a training program for community-based resource workers on cleft lip and palate and cleft speech. J Cleft Lip Palate and Craniofacial Anomalies. 2017; 4(2):138.

15. Morin D, Rivard M, Crocker AG, Boursier CP, Caron J. Public attitudes towards intellectual disability: A multidimensional perspective. J Intellect Disabil Res. 2013;57(3):279-292.

16. Rao AJ, Sharmila M, Rishitha N. Awareness of and attitudes to disability in rural and urban communities of Andhra Pradesh, India - A comparative study.
International Journal of Disability Comunity and Rehabilitation. 2000; 2(1).

17. Savithri SR, Rajasudhakar R, Priya MB. Aishwarya N. Effectiveness of orientation program on communication disorders for ASHA workers of Mysuru, Mandya and Chamrajanagar districts. Int $\mathbf{J}$ Health Sci Res. 2018; 8(11):1-7.

How to cite this article: Varghese A, Ojha T. Efficacy of a speech-language development and disorders awareness lecture among pre-primary school teachers in Lucknow. Int $J$ Health Sci Res. 2021; 11(5): 94-102. DOI: https://doi.org/ 10.52403/ijhsr.20210514

$* * * * * *$ 